\title{
Alloscardovia omnicolens gen. nov., sp. nov., from human clinical samples
}

Correspondence

Geert Huys

geert.huys@UGent.be

\author{
Geert Huys, ${ }^{1}$ Marc Vancanneyt, ${ }^{2}$ Klaas D'Haene, ${ }^{1}$ Enevold Falsen, ${ }^{3}$ \\ Georges Wauters ${ }^{4}$ and Peter Vandamme ${ }^{1}$
}

\author{
${ }^{1}$ Laboratory of Microbiology, Ghent University, K. L. Ledeganckstraat 35, B-9000 Ghent, \\ Belgium \\ ${ }^{2}$ BCCM/LMG Bacteria Collection, Ghent University, K. L. Ledeganckstraat 35, B-9000 Ghent, \\ Belgium \\ ${ }^{3}$ CCUG Culture Collection, University of Göteborg, Guldhedsgatan 10, SE-413 46 Göteborg, \\ Sweden \\ ${ }^{4}$ University of Louvain, Microbiology Unit UCL 5490, Avenue Hippocrate 54, B-1200 Brussels, \\ Belgium
}

The taxonomic position of 12 isolates tentatively assigned to the genus Bifidobacterium on the basis of a limited phenotypic characterization was examined. The isolates were collected between 1978 and 2005 in Belgium, Sweden and Norway, and originated from various human clinical samples, including urine, blood, urethra, oral cavity, tonsil, and abscesses of lung and aortic valve. On the basis of band number and clustering analysis, repetitive DNA element-based PCR fingerprinting using the BOXA1R and $(G T G)_{5}$ primers indicated that the clinical isolates represented a taxon probably not belonging to the genus Bifidobacterium. Analysis of $16 \mathrm{~S}$ rRNA gene sequence similarities revealed that the isolates were most closely affiliated to Parascardovia denticolens LMG $18312^{\top}$ (93.0-93.2\%), Scardovia inopinata LMG $18313^{\top}$ (92.9-93.1\%) and other members of the Bifidobacteriaceae, indicating that the isolates belong to a novel genus within that family. This observation was further substantiated by the results of partial sequencing of the heat-shock protein 60 gene ( $h s p 60)$ and determination of the DNA G $+\mathrm{C}$ contents (47.3-48.3 mol\%). Members of the novel taxon can be phenotypically distinguished from $S$. inopinata, $P$. denticolens and Gardnerella vaginalis by the ability to grow on agar under aerobic conditions and on the basis of positive reactions for acid production from L-arabinose, raffinose, salicin and D-xylose. Unambiguous phenotypic differentiation from Aeriscardovia aeriphila and Bifidobacterium species may be difficult, so phenotypic analyses should be complemented by molecular methods. The values for DNA-DNA binding among four members of the novel genus were in the range of $89-100 \%$, indicating that the strains should be considered as a single novel species of a novel genus, for which the name Alloscardovia omnicolens gen. nov., sp. nov. is proposed. The type strain of Alloscardovia omnicolens is CCUG $31649^{\top}$ (=LMG $23792^{\top}$ ).
Upon its first description (Stackebrandt et al., 1997), the family Bifidobacteriaceae consisted of only two genera, namely Bifidobacterium (a taxonomically complex genus that currently contains 29 species with validly published names; http://www.bacterio.cict.fr/b/bifidobacterium.html) and Gardnerella (containing only Gardnerella vaginalis). Although the members of this family are considered as essentially non-pathogenic, a number of exceptions have been reported. $G$. vaginalis has been recognized as an

The GenBank/EMBL/DDBJ accession numbers for the partial $16 \mathrm{~S}$ rRNA gene sequences and the partial hsp60 gene sequences determined in this work are AM419458-AM419461 and AM419462AM419467, respectively, as listed in Figs 2 and 3. opportunistic pathogen in bacterial vaginosis (Forsum et al., 2005), whereas Bifidobacterium dentium is commonly found in human dental plaque and caries and probably contributes to caries pathology (Modesto et al., 2006). In contrast, the clinical relevance of Bifidobacterium scardovii, which has so far been isolated exclusively from human clinical specimens, is currently unknown (Hoyles et al., 2002). Recently, the family Bifidobacteriaceae was expanded to contain three novel genera encompassing species that were formerly considered as atypical Bifidobacterium species. First, Jian \& Dong (2002) transferred two species isolated from human dental caries, Bifidobacterium inopinatum and Bifidobacterium denticolens (Crociani et al., 1996), to two novel genera as Scardovia inopinata and 
Parascardovia denticolens, respectively. A third novel genus arose from a study on the biodiversity of bifidobacteria present in a porcine caecum (Simpson et al., 2003). In the latter study, a group of unknown isolates was provisionally classified as 'Bifidobacterium aerophilum' and later named Aeriscardovia aeriphila (Simpson et al., 2004). In the present study, we investigated the taxonomic position of 12 human clinical isolates tentatively assigned to the genus Bifidobacterium on the basis of limited phenotypic characterization. Taxonomic positioning based on sequencing of the $16 \mathrm{~S}$ rRNA gene and the heat-shock protein 60 (HSP60) gene revealed that the isolates belong to a novel species and genus.

With the exception of isolate LMG 23791, which originated in Belgium from a patient with a lung abscess, all isolates were obtained from the Culture Collection, University of Göteborg (CCUG), Sweden (http://www.ccug.se). The CCUG isolates were collected through clinical laboratory services in Sweden and Norway from 1978 to 2005 and originated from various human clinical samples, including urine, blood, urethra, oral cavity, tonsil and abscesses of the lung and aortic valve (for details, see Fig. 1). Bacterial reference strains for the genus Bifidobacterium were obtained from the BCCM/LMG Bacteria Collection, Ghent University, Belgium (http://bccm.belspo.be/db/). Isolates were routinely grown on modified Columbia agar [MCA, containing $\left(\mathrm{l}^{-1}\right.$ distilled water) $23 \mathrm{~g}$ special peptone (L37; Oxoid), $1 \mathrm{~g}$ soluble starch, $5 \mathrm{~g} \mathrm{NaCl}, 0.3 \mathrm{~g}$ L-cysteine hydrochloride, $5 \mathrm{~g}$ glucose and $15 \mathrm{~g}$ agar] at $37^{\circ} \mathrm{C}$ under anaerobic conditions $\left(\mathrm{N}_{2} / \mathrm{H}_{2} / \mathrm{CO}_{2}, 84: 8: 8\right)$ unless otherwise stated.

Because the 12 human clinical isolates were received as Bifidobacterium-like organisms, they were first examined using repetitive DNA element PCR (rep-PCR) fingerprinting using the primer BOXA1R (BOX-PCR). Previously, a taxonomic framework based on BOX-PCR profiles was constructed, allowing the identification of a wide range of bifidobacteria at species, subspecies and, potentially, strain level (Masco et al., 2003). DNA extraction, BOX-PCR and data processing were performed essentially as described previously (Masco et al., 2003). BOX-PCR analysis of the 12 clinical isolates yielded atypical fingerprints showing 5-7 bands (data not shown); bifidobacterial BOX-PCR fingerprints typically contain $>20$ bands (Masco et al., 2003).
Subsequently, a second rep-PCR fingerprinting technique based on the use of the $(\mathrm{GTG})_{5}$ primer $\left[(\mathrm{GTG})_{5}-\mathrm{PCR}\right]$ was employed as described previously (Masco et al., 2003). (GTG) $)_{5}$-PCR fingerprinting yielded more bands than BOXPCR, and clustering analysis reconfirmed that the clinical isolates represented a group of isolates probably not belonging to the genus Bifidobacterium (Fig. 1). In addition, each of the isolates displayed a unique (GTG) $)_{5}$-PCR fingerprint, indicating that the collection under study consisted of 12 different strains.

The complete 16S rRNA gene sequences of strains CCUG 34444 (GenBank accession no. AJ278695) and CCUG 26938 (accession no. AJ278694) were previously deposited in GenBank/EMBL/DDBJ under the provisional unpublished species name 'Bifidobacterium urinalis'. In the present study, the 16S rRNA gene sequences of four additional strains, CCUG 18650, CCUG $31649^{\mathrm{T}}$, CCUG 44766 and LMG 23791, were determined. In addition, partial sequences ( $\sim 590 \mathrm{bp}$ ) of the gene encoding HSP60 were determined for the same six strains. The $h s p 60$ gene has been proposed as an alternative phylogenetic marker for the genus Bifidobacterium (Jian et al., 2001) and has since been included in the description of several novel members of the Bifidobacteriaceae (Jian \& Dong, 2002; Simpson et al., 2004). Genomic DNA was extracted as described previously (Masco et al., 2003). Amplification, purification and sequencing of $16 \mathrm{~S}$ rRNA and $h s p 60$ genes were performed according to Vancanneyt et al. (2006) and Jian et al. (2001), respectively. The sequences obtained for both genes were used for BLAST searches in EMBL; the highest levels of similarities were found with respect to Scardovia, Parascardovia and other members of the Bifidobacteriaceae. Phylogenetic trees that included reference sequences of members of the family Bifidobacteriaceae were constructed for the 16S rRNA and hsp60 gene sequences by using the neighbour-joining method and the BioNumerics (version 4.0) software package (Applied Maths). Unknown bases were excluded from the analysis. The statistical reliability of the trees was evaluated by bootstrap analysis of 500 replicates, and the tree topology was also confirmed using maximum-parsimony and maximum-likelihood cluster analysis (data not shown). Strains CCUG 18650, CCUG 26938, CCUG $31649^{\mathrm{T}}$, CCUG 34444, CCUG 44766 and LMG 23791 showed 16S rRNA gene sequence similarity in the range $99.5-100 \%$, indicating

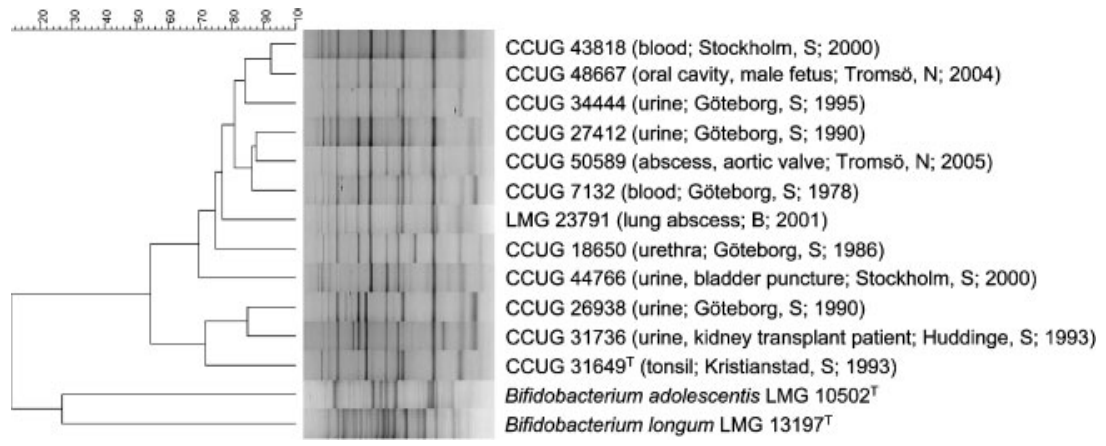

Fig. 1. Dendrogram showing clustering of digitally inverted (GTG) $)_{5}$-PCR fingerprints of the 12 Bifidobacterium-like human clinical isolates in comparison with the type strains of Bifidobacterium adolescentis and Bifidobacterium longum. The dendrogram was obtained with the UPGMA, using Pearson's product-moment similarity coefficient. The clinical source, geographical origin ( $\mathrm{B}$, Belgium; $\mathrm{N}$, Norway; S, Sweden) and year of isolation of the 12 unknown isolates are indicated. 
that they represent a phylogenetically homogeneous taxon (Fig. 2). The highest levels of similarity with respect to members of the Bifidobacteriaceae were found with P. denticolens LMG $18312^{\mathrm{T}}(93.0-93.2 \%)$ and S. inopinata LMG $18313^{\mathrm{T}}(92.9-93.1 \%)$. Sequence similarities for the six strains with respect to the other family members, namely Aeriscardovia aeriphila LMG $21773^{\mathrm{T}}$, G. vaginalis LMG $7832^{\mathrm{T}}$ and Bifidobacterium species, ranged from 89.8 to $91.8 \%$. Analysis of a partial $h s p 60$ gene sequence confirmed the high levels of similarity among the six strains of the Bifidobacterium-like group (97.1-99.6\%) and clearly separated this group from its closest phylogenetic neighbours, G. vaginalis $\mathrm{LMG} 7832^{\mathrm{T}}$ (80.3-81.5\% sequence similarity), S. inopinata LMG $18313^{\mathrm{T}}(75.0-77.7 \%)$ and P. denticolens LMG $18312^{\mathrm{T}}$ (74.6-77.3\%) (Fig. 3). Collectively, the 16S rRNA and $h s p 60$ gene sequence analyses indicate that the group of 12 clinical strains is positioned on a distinct branch within the family Bifidobacteriaceae and is sufficiently divergent from the other members of this family to require placement in a novel genus.

The $\mathrm{G}+\mathrm{C}$ contents ( $\mathrm{mol} \%$ ) of four strains were determined using the enzymic degradation method described by Mesbah et al. (1989). The nucleoside mixture was separated by HPLC using a Waters SymmetryShield C8 column maintained at $37^{\circ} \mathrm{C}$. The solvent was $0.02 \mathrm{M}\left(\mathrm{NH}_{4}\right) \mathrm{H}_{2} \mathrm{PO}_{4}$ ( $\mathrm{pH} 4.0$ ) with $1.5 \%$ acetonitrile. Non-methylated $\lambda$-phage DNA (Sigma) was used as the calibration reference. The DNA G +C contents of strains CCUG 26938, CCUG $31649^{\mathrm{T}}$, CCUG 34444 and LMG 23791 were $48.3,48.0,47.3$ and $48.0 \mathrm{~mol} \%$, respectively. These values are consistent with the phylogenetic positioning of these strains within the family Bifidobacteriaceae, with S. inopinata (45 mol\%),

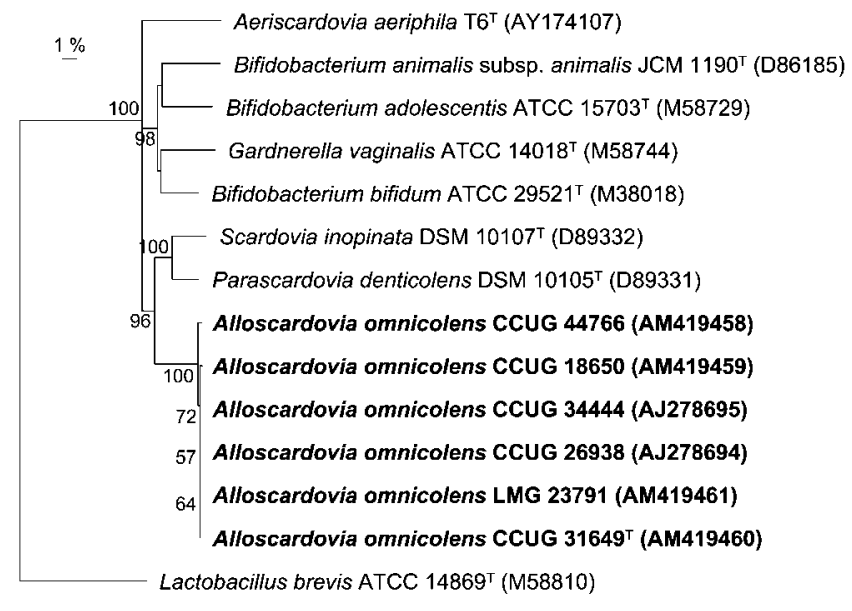

Fig. 2. Neighbour-joining phylogenetic tree, derived from analysis of nearly-complete 16S rRNA gene sequences (stretches of $1404 \mathrm{bp}$ ), showing the position of six of the novel strains in the family Bifidobacteriaceae. Lactobacillus brevis ATCC $14869^{\top}$ was used as an outgroup. Bootstrap percentages (based on 500 replications) at or above $50 \%$ are indicated at branch points. Bar, 1 nucleotide substitution per 100 nucleotides.

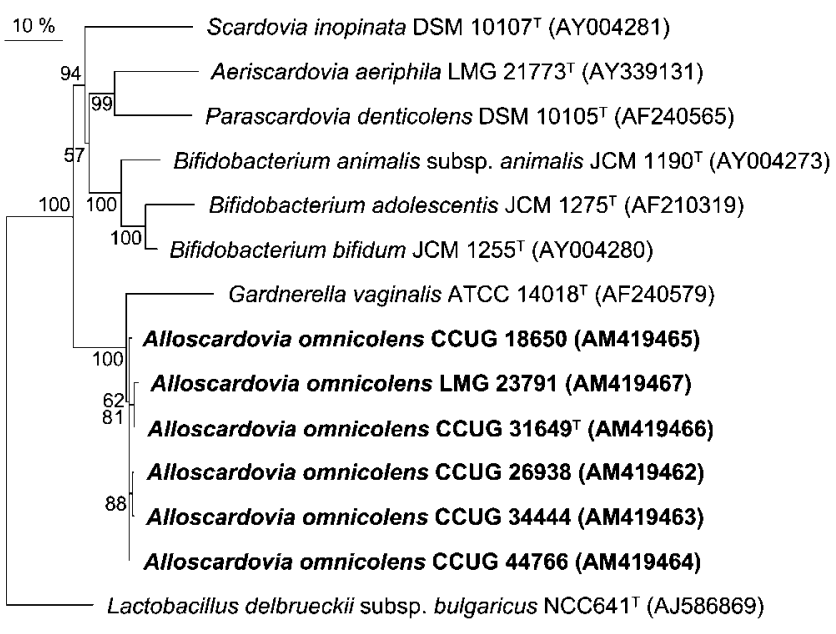

Fig. 3. Neighbour-joining phylogenetic tree, derived from analysis of partial hsp60 gene sequences (stretches of $458 \mathrm{bp}$ ), showing the position of six of the novel strains in the family Bifidobacteriaceae. Lactobacillus delbrueckii subsp. bulgaricus $\mathrm{NCC} 641^{\top}$ was used as an outgroup. Bootstrap percentages (based on 500 replications) at or above $50 \%$ are indicated at branch points. Bar, 10 nucleotide substitutions per 100 nucleotides.

P. denticolens (55 mol\%) and G. vaginalis (41.8-43.0 mol\%) as the closest relatives (Table 1).

To determine the DNA relatedness among members of the novel taxon at species level, DNA-DNA hybridizations were performed between strains CCUG 26938, CCUG $31649^{\mathrm{T}}$, CCUG 34444 and LMG 23791. Total genomic DNA was prepared using a combination of the protocols of Marmur (1961) and Pitcher et al. (1989), as described previously (Goris et al., 1998) and using mutanolysin for cell lysis. DNA-DNA hybridizations were performed with biotinlabelled probes in microplate wells according to Ezaki et al. (1989), with the modifications of Goris et al. (1998), using an HTS7000 Bio Assay Reader (Perkin Elmer) for the fluorescence measurements. Hybridization was performed at $37^{\circ} \mathrm{C}$ in the presence of $50 \%$ formamide. Reciprocal experiments were performed for every pair of strains: the standard deviations ranged from 3 to $12 \%$. The values for DNA-DNA binding among strains CCUG 26938, CCUG $31649^{\mathrm{T}}$, CCUG 34444 and LMG 23791 were in the range $89-100 \%$. As the recognized DNA-DNA binding threshold for allocating bacterial isolates to the same species is $\geqslant 70 \%$ (Wayne et al., 1987), it can be concluded that these four strains [along with the other eight CCUG strains included in $(\mathrm{GTG})_{5}$-PCR fingerprinting and phylogenetic analyses] should be considered as representing a single novel species.

Growth characteristics and primary phenotypic characteristics of the 12 clinical strains were determined on MCA or on modified MRS (mMRS) agar containing MRS agar (CM361; Oxoid) supplemented with $0.05 \%$ (w/v) cysteine hydrochloride. Aerobic and anaerobic growth was tested at $28,37,40,45$ and $50{ }^{\circ} \mathrm{C}$. The carbohydrate-fermentation 
Table 1. Differential characteristics of the novel strains (Alloscardovia omnicolens gen. nov., sp. nov.) and other members of the Bifidobacteriaceae

Taxa: 1, Alloscardovia omnicolens; 2, Scardovia inopinata; 3, Parascardovia denticolens; 4, Aeriscardovia aeriphila; 5, Gardnerella vaginalis; 6, Bifidobacterium. Data are from this study and previous studies (Crociani et al., 1996; Gavini et al., 1991; Jian \& Dong, 2002; Piot et al., 1980; Simpson et al., 2004). + , Positive; -, negative; v, variable reaction.

\begin{tabular}{|lcccccc|}
\hline Characteristic & $\mathbf{1}$ & $\mathbf{2}$ & $\mathbf{3}$ & $\mathbf{4}$ & $\mathbf{5}$ & $\mathbf{6}$ \\
\hline Aerobic growth on agar & + & - & - & + & + & $(+)^{*}$ \\
Temperature range for growth $\left({ }^{\circ} \mathrm{C}\right)$ & $28-45$ & $27-44$ & $27-44$ & $30-46$ & $30-37$ & $25-46$ \\
Acid from: & & & & & & \\
$\quad$ L-Arabinose & + & - & $\mathrm{V}$ & + & $\mathrm{V}$ & $\mathrm{V}$ \\
Raffinose & + & + & + & + & - & $\mathrm{V}$ \\
Salicin & + & + & + & + & - & $\mathrm{V}$ \\
D-Xylose & + & + & - & $\mathrm{V}$ & $\mathrm{V}$ & $\mathrm{V}$ \\
DNA G+C content (mol\%) & $47.3-48.3$ & 45 & 55 & 54.7 & $41.8-43.0$ & $55-67$ \\
\end{tabular}

*Bifidobacterium minimum grows at the initial inoculation point on mMRS agar.

patterns of the strains were determined using API Rapid ID $32 \mathrm{~A}$ and API $20 \mathrm{~A}$ test strips (bioMérieux), according to the manufacturer's instructions, at $37^{\circ} \mathrm{C}$ under anaerobic conditions. Tests in the API Rapid ID 32A and API 20A systems were read after 4 and 48 h, respectively. Haemolysis activity was checked on MCA supplemented with $5 \%$ horse blood at $37^{\circ} \mathrm{C}$ under anaerobic conditions. The novel taxon can be distinguished phenotypically from $S$. inopinata, $P$. denticolens and $G$. vaginalis by its ability to grow on agar under aerobic conditions and on the basis of its positive reactions for acid production from L-arabinose, raffinose, salicin and D-xylose (Table 1). Unambiguous phenotypic differentiation from Aeriscardovia aeriphila and Bifidobacterium species may be difficult, so phenotypic tests should be complemented by molecular methods, as described here. A detailed phenotypic description of the novel taxon is given below.

Taken together, the evidence provided by $(\mathrm{GTG})_{5}-\mathrm{PCR}$ fingerprinting, $16 \mathrm{~S}$ rRNA and $h s p 60$ gene sequencing, $\mathrm{G}+\mathrm{C}$ content analysis, DNA-DNA hybridizations and phenotypic characterization indicate that the 12 strains listed in Fig. 1 represent a novel taxon within the family Bifidobacteriaceae, for which the name Alloscardovia denticolens gen. nov., sp. nov. is proposed. The genus name Alloscardovia is in line with the nomenclature of the genera that are, on the basis of 16S rRNA gene sequence similarity, most closely related phylogenetically (i.e. Scardovia, Parascardovia and Aeriscardovia).

\section{Description of Alloscardovia gen. nov.}

Alloscardovia (Al.lo.scar.do'vi.a. Gr. adj. allos different; N.L. fem. n. Scardovia a bacterial generic name; N.L. fem. n. Alloscardovia organism related to, but different from, Scardovia and related genera).
Gram-positive, catalase- and oxidase-negative, non-motile, non-spore-forming, short irregularly shaped rods. Optimal growth occurs under anaerobic conditions on MCA or mMRS after $24 \mathrm{~h}$ at $37^{\circ} \mathrm{C}$, but slow aerobic growth $(72 \mathrm{~h})$, producing pinpoint-sized colonies, is also observed on MCA. The DNA G + C content of the type species is 47.3$48.3 \mathrm{~mol} \%$. Isolated from various human clinical samples, but no data are currently available on potential pathogenic relevance or virulence factors. On the basis of $16 \mathrm{~S}$ rRNA and HSP60 gene sequence analyses, Alloscardovia is a member of the family Bifidobacteriaceae. Only one species has been described for this genus, i.e. the type species, Alloscardovia omnicolens.

\section{Description of Alloscardovia omnicolens sp. nov.}

Alloscardovia omnicolens (om.ni.co'lens. L. masc. adj. omnis every; L. v. colere to dwell; L. pres. part. colens dwelling; N.L. part. adj. omnicolens dwelling everywhere in the human body).

Displays the following properties in addition to those given in the genus description. Cells are arranged singly or in pairs. Anaerobic growth on MCA occurs at $28^{\circ} \mathrm{C}$ (after $72 \mathrm{~h}$ ), $37-40{ }^{\circ} \mathrm{C}$ (after $24 \mathrm{~h}$ ) and $45^{\circ} \mathrm{C}$ (after $96 \mathrm{~h}$ ), but not at $50^{\circ} \mathrm{C}$ (after $96 \mathrm{~h}$ ). Little or no $\beta$-haemolysis is produced on blood-supplemented MCA. All strains ferment D-glucose, sucrose, D-maltose, salicin, D-xylose, L-arabinose and raffinose. None ferments rhamnose (except strain CCUG 31736), sorbitol (except strains CCUG 27412 and CCUG 31736), mannitol (except strains CCUG 27412 and CCUG 31736) or glycerol (except strain CCUG 31736). All strains exhibit $\alpha$-galactosidase, $\beta$-galactosidase, $\alpha$-glucosidase, $\beta$-glucosidase, $\alpha$-arabinosidase (except strain CCUG 44766), arginine arylamidase, proline arylamidase, phenylalanine arylamidase, leucine arylamidase, tyrosine arylamidase, glycine arylamidase, histidine arylamidase and serine arylamidase 
activities. None of the strains exhibits arginine dihydrolase, $\beta$-galactosidase 6-phosphate, $\beta$-glucuronidase, $N$-acetyl- $\beta$ glucosaminidase, glutamic acid decarboxylase, $\alpha$-fucosidase, alkaline phosphatase, leucyl glycine arylamidase, pyroglutamic acid arylamidase, alanine arylamidase, glutamyl glutamic acid arylamidase or urease activities or indole production. Aesculin is hydrolysed. Gelatin is not liquefied and nitrate is not reduced to nitrite. Isolated from various human clinical samples, including urine, blood, urethra, oral cavity, tonsil and abscesses of lung and aortic valve.

The type strain, CCUG $31649^{\mathrm{T}}\left(=\mathrm{LMG} 23792^{\mathrm{T}}\right)$, was isolated from the tonsil of a 25-year-old woman from Kristianstad, Sweden, in 1993. The DNA G + C content of this strain is $48.0 \mathrm{~mol} \%$. Strains CCUG 7132, CCUG 50589 and CCUG 26938, which also belong to the species, have been deposited in the BCCM/LMG Bacteria Collection as LMG 23793-LMG 23795, respectively.

\section{Acknowledgements}

Parts of this work were supported by a grant from the European Commission ('Biosafety Evaluation of Probiotic Lactic Acid Bacteria Used for Human Consumption'; PROSAFE; QLRT-2001-01273). G.H. is a post-doctoral fellow of the Fund for Scientific Research Flanders (F.W.O. - Vlaanderen), Belgium. E. F. is grateful to many Swedish and Norwegian clinical microbiologists for depositing their strains, and Dr Knut Lincoln in particular for his outstanding analytical work. Renata Coopman, Elisabeth Inganäs and Maria Ohlén are thanked for excellent technical assistance.

\section{References}

Crociani, F., Biavati, B., Alessandrini, A., Chiarini, C. \& Scardovi, V. (1996). Bifidobacterium inopinatum $\mathrm{sp}$. nov. and Bifidobacterium denticolens sp. nov., two new species isolated from human dental caries. Int J Syst Bacteriol 46, 564-571.

Ezaki, T., Hashimoto, Y. \& Yabuuchi, E. (1989). Fluorometric deoxyribonucleic acid-deoxyribonucleic acid hybridization in microdilution wells as an alternative to membrane-filter hybridization in which radioisotopes are used to determine genetic relatedness among bacterial strains. Int J Syst Bacteriol 39, 224-229.

Forsum, U., Holst, E., Larsson, P. G., Vasquez, A., Jakobsson, T. \& Mattsby-Baltzer, I. (2005). Bacterial vaginosis - a microbiological and immunological enigma. APMIS 113, 81-90.

Gavini, F., Pourcher, A.-M., Neut, C., Monget, D., Romond, C., Oger, C. \& Izard, D. (1991). Phenotypic differentiation of bifidobacteria of human and animal origin. Int J Syst Bacteriol 41, 548-557.

Goris, J., Suzuki, K., De Vos, P., Nakase, T. \& Kersters, K. (1998). Evaluation of a microplate DNA-DNA hybridization method compared with the initial renaturation method. Can J Microbiol 44, 1-7.

Hoyles, L., Inganäs, E., Falsen, E., Drancourt, M., Weiss, N., McCartney, A. L. \& Collins, M. D. (2002). Bifidobacterium scardovii sp. nov., from human sources. Int J Syst Evol Microbiol 52, 995-999.

Jian, W. \& Dong, X. (2002). Transfer of Bifidobacterium inopinatum and Bifidobacterium denticolens to Scardovia inopinata gen. nov., comb. nov., and Parascardovia denticolens gen. nov., comb. nov., respectively. Int J Syst Evol Microbiol 52, 809-812.

Jian, W., Zhu, L. \& Dong, X. (2001). New approach to phylogenetic analysis of the genus Bifidobacterium based on partial HSP60 gene sequences. Int J Syst Evol Microbiol 51, 1633-1638.

Marmur, J. (1961). A procedure for the isolation of deoxyribonucleic acid from microorganisms. J Mol Biol 3, 208-218.

Masco, L., Huys, G., Gevers, D., Verbrugghen, L. \& Swings, J. (2003). Identification of Bifidobacterium species using rep-PCR fingerprinting. Syst Appl Microbiol 26, 557-563.

Mesbah, M., Premachandran, U. \& Whitman, W. B. (1989). Precise measurement of the $\mathrm{G}+\mathrm{C}$ content of deoxyribonucleic acid by high-performance liquid chromatography. Int J Syst Bacteriol 39, 159-167.

Modesto, M., Biavati, B. \& Mattarelli, P. (2006). Occurrence of the family Bifidobacteriaceae in human dental caries and plaque. Caries Res 40, 271-276.

Piot, P., Van Dyck, E., Goodfellow, M. \& Falkow, S. (1980). A taxonomic study of Gardnerella vaginalis (Haemophilus vaginalis) Gardner and Dukes 1955. J Gen Microbiol 119, 373-396.

Pitcher, D. G., Saunders, N. A. \& Owen, R. J. (1989). Rapid extraction of bacterial genomic DNA with guanidium thiocyanate. Lett Appl Microbiol 8, 151-156.

Simpson, P. J., Stanton, C., Fitzgerald, G. F. \& Ross, R. P. (2003). Genomic diversity and relatedness of bifidobacteria isolated from a porcine cecum. J Bacteriol 185, 2571-2581.

Simpson, P. J., Ross, R. P., Fitzgerald, G. F. \& Stanton, C. (2004). Bifidobacterium psychraerophilum sp. nov. and Aeriscardovia aeriphila gen. nov., sp. nov., isolated from a porcine caecum. Int J Syst Evol Microbiol 54, 401-406.

Stackebrandt, E., Rainey, F. A. \& Ward-Rainey, N. L. (1997). Proposal for a new hierarchic classification system, Actinobacteria classis nov. Int J Syst Bacteriol 47, 479-491.

Vancanneyt, M., Naser, S. M., Engelbeen, K., De Wachter, M., Van der Meulen, R., Cleenwerck, l., Hoste, B., De Vuyst, L. \& Swings, J. (2006). Reclassification of Lactobacillus brevis strains LMG 11494 and LMG 11984 as Lactobacillus parabrevis sp. nov. Int J Syst Evol Microbiol 56, 1553-1557.

Wayne, L. G., Brenner, D. J., Colwell, R. R., Grimont, P. A. D., Kandler, O., Krichevsky, M. I., Moore, L. H., Moore, W. E. C., Murray, R. G. E. \& other authors (1987). International Committee on Systematic Bacteriology. Report of the ad hoc committee on reconciliation of approaches to bacterial systematics. Int $J$ Syst Bacteriol 37, 463-464. 